\title{
A Brief Analysis of Imitation and Innovation in Academic Field
}

\author{
Qing-Feng SHEN ${ }^{1, a}$, Ying ZHENG $^{2, b}$ \\ ${ }^{1,2}$ Basic Science Dept. of Aviation University of Air Force, Changchun, China. \\ asqf1998@163.com, bsqf1998@163.com
}

Keywords: Imitation, Innovation, Academic field.

\begin{abstract}
The academic field has four main characters and one of them is about the innovation that "is decided by the need of scientific development". Nowadays, there is a kind of repetition even plagiarism without wrenching one's brains and those people, for various reasons, write this kind of paper maybe just want to increase the number of their academic papers. In fact, we can see clearly that simple imitation is useless and it is just a process of innovation and what we need is the true innovation in academic fields which is the result of effective imitation.
\end{abstract}

\section{Introduction}

According to the standard definition of academic paper delivered by our country, academic paper is a kind of writing document which contains new scientific research achievement, innovative knowledge and scientific records for reading, communication and discussion or delivering in academic journals. Based on the definition of academic paper, we may easily figure out the concept of the academic field which means the concerning area that authors and scholars of academic papers are engaged in. They do their research in the fields concerning about their majors. The academic field has four main characters and one of them is about the innovation that "is decided by the need of scientific development". Scholars systematically synthesize problems, phenomena, achievements and ideas in other related papers into their views to concentrate on the information in the vision of their own specialty knowledge. This process needs creativity and innovation toward academic field and the innovation ability is what we should seek constantly. However, nowadays there congest academic papers which contain no innovation at all in academic field. These papers are like the speaking of a parrot and they just imitate the words, research achievements and ideas of other scholars who have already innovated in the specific field. In fact, that is a kind of repetition even plagiarism without wrenching one's brains and those people, for various reasons, write this kind of paper just want to increase the number of their academic papers. They care for the quantity instead of the quality of their academic paper. Thus, we can see clearly that simple imitation is useless and it is just a process of innovation and what we need is the true innovation in academic fields which is the result of effective imitation.

As Manakins put it, "Innovation is the act of ingenuity while imitation is copying. They are like twins but unidentical twins would always be at crossroads with each other. Would we allow imitation to outshine innovation? Let's fight against imitation so that we can continue innovating." Just like this saying, we need innovation everywhere and this paper mainly deals with the relationship of imitation and innovation in academic field. There are two main conflicting factors we should take into consideration in which the first one is the imitation of discoveries and other scholars' opinions as one's own "new point of view" and this is easy to do because one can just repeat what others' saying. The second and more significant one is the innovation in academic field and it is difficult because one has to read a lot and do great deal of research work for a long time even years but the outcome one gets totally belongs to him. Even so, it is wrong to simply advocate innovation and at the same time ignore the importance and usefulness of imitation. We should advocate innovation while we should not deny imitation because there is innovation in imitation. "Successful imitation is a kind of self-innovation", also we are very familiar with this famous saying said by the great scientist Newton "I can see further than others because I am standing on the shoulders of giants" These two sentences may well illustrate the special relationship between the two factors and usually imitation serves as foil for innovation. What we have to do is just to avoid the phenomenon of blind imitation without consideration of innovation in academic field. At first 
sight, the issue of the two conflicting factors of imitation and innovation seems straightforward however it is really complicated. Prior to analyze the imitation and innovation, it is necessary to take account of some phenomena originated in blind imitation.

\section{Literature Review}

Looking through academic papers in the learned journals of many universities, we can easily find out many so-called papers, which should stand for the comparatively higher level in the concerning innovative fields, lack of readability because usually the authors convey and copy other scholars. This causes the scarcity of significant and valuable new views in academic writing which directly influences the improvement of pioneer in academic field of our country. Sometimes, in order to say a sentence of his own, the author always cites thousands of words of tens of famous persons. Quite a lot of the scholars even experts in our minds who may be the most outstanding men in their fields are just doing a kind of repetitive work. The ideas of them are right but we can learn nothing from them. Many leaders of our country have pointed out clearly many times in open occasions that innovation is the soul of the progress of a country and a nationality. This innovation delivered by the leaders definitely includes the innovation in academic field. It is the time that the whole society is advocating innovation in all fields and the concept of innovation is gradually accepted by more and more people, and then under such a circumstance how can the atmosphere of not innovating in academic field be so prevalent? A great deal has been written about the inappropriate use by authors or scholars of views originated by others. The time is ripe for a deeper consideration of the correct relationship between innovation and imitation.

\section{Argumentation}

Scholars without ideas of innovation usually cite more of famous persons and their fruit while their own voice is scarce, limit and weak. So, I cannot help wondering: is it indeed right only if other famous persons have the same view? If it is right, then what are the innovative points of view? It maintaining for long time, how can our academic fields develop without innovative thought or spirit? Therefore, by no means should we accept these kinds of blind imitation. Blind imitation at last will drop into the scope of plagiarism and this will do great harm to our development academic field even progress of our society. However, on the other hand, there are really some useful functions of imitation except those blind ones.

In my opinion, I constantly hold that imitation is indispensable toward innovation but it can only serve as a basic method to improve scholar's innovative ability. "Imitation is the preliminary stage for writing." Chen (2005). We should draw a line of imitation from plagiarism, that is to say, when imitating other scholars, we must not plagiarize from them by words or sentences, instead what we can do is to learn the method and skill of their writing. If we plagiarize instead of imitating from the view of the perspective of the whole paper, we just do something like the parrot speaking and the paper we write will be like a bowl of fresh water without any taste. People who drink the water will feel dull and disappointed at their not learning any valuable information from our papers which is irresponsible to not only academic field but also readers. We do not accept plagiarism but we cannot negate the importance of imitation because simply saying it is a kind of imitating of the methodology of a paper not the words. In fact, the process and destination of imitation is something like the process of learning, absorbing and innovating and finally after imitation we may get to innovation. From this aspect, we can see that good innovation comes from meticulous imitation and imitation is the existing condition of innovation. For example, Lu Xun once read the a work called Madman's Dairy written by Gogol Nikolay(1809-1852)which helped him to get inspiration and through his efforts of learning and comprehension Lu Xun finally finished his own Madman's Dairy.

However sometimes, we must abandon imitation to innovate audaciously. Not all innovations in an academic field derived from imitation will be acceptable to their researchers because in different times and different environments, people would have different understandings toward the same thing. Innovation must be proper to follow the actual trend and only innovations which stand in front of the research field can have the eternal vigor; others will not be interesting for a long time because they cannot satisfy what the researchers need. We may have read a lot of articles; we admire the talent of the author 
and appreciate the wonderful plot in them while usually we cannot write out an amazing article. Is it really so difficult? At this stage, we should arrange what we have learned for a preparation and make innovation bravely. After lots of learning and imitation, we must get rid of imitation to innovate by ourselves otherwise we cannot be acceptable by others all the time and we cannot get rid of the fetters of imitation. It is just like this: imitation is the walking stick helping us to walk while at last we must run, hence we should leave the stick and run with our own feet.

From above, the relationship between imitation and innovation is that innovation needs imitation and imitation works for better innovation; they complement each other. "Imitation of a discovery can be socially desirable in a world of sequential and complementary innovation because it helps the imitator develop further inventions. And because the imitator may have valuable ideas not available to the original discoverer, the overall pace of innovation may thereby be enhanced." Bessen \& Maskin (1999). Of course, other scholars will also duplicate the same process and we can see that from imitation to innovation and vice versa is a circulated process which pushes researches in the academic fields to develop forward.

We should not ignore the importance of imitation which is a key process even of the same weight of the innovation in this circle. Imitation brews and then innovation bursts. Imitation is a long process and innovation may appear only in a twinkling, so we should experience imitation for long time during which period we learn and accumulate a lot, then at last we make out a brand new theories or something like that to show the result of our imitation---innovation. We must not lose patience and confidence in the long process of imitation, we should remind ourselves constantly that we are on the way of success and the painstaking work we are enduring worth the final result of our successful paper. I think by this way, scholars of academic field can lay down on their desks to throw themselves into the research work and they can not care for the quantity of their papers any longer. They want to be famous and they write great deal of papers during their lives but we can not remember them while abiding by the regular pattern of imitation and innovation, they may write only one paper in their lives, however we can remember this paper of highest grade and its author.

\section{Discussion}

Many academic writing devotees find it hard to innovate because the fields they are engaged in are full of researchers and it is really not easy to make out a different view from other scholars, a more valuable view than the originals. However, even in fields that seem to have been well covered by other scholars, possibilities for further research can often be found. Otherwise, there will be no progress in academic field even society. Then the crucial point is that how to innovate in such well covered fields.

First, "Imitation and then innovation, reflection upon action through peer and teacher assessment and then adjusted future action." Paxton(2003). We can use imitation as a learning method. We can imitate the process of innovation of other scholars to see whether we can get the similar outcome of them. The value of this process lies in two aspects: it is a process of learning the knowledge which is considered to be standing in the most advanced area of the subject we are engaged in; it is also a process of training to make us qualified and enabled to get innovative ideas. So, imitation can help us go close to innovation. Constant discussion with our peers and teachers will also help us to go in the right way and we can make adjustment in time. We should consult and sometimes cooperate with others because in the long process of imitation, we must keep the correct direction or we can not reach the final innovation in our research field.

Second, recently published books or developments in current events can afford new insight into existing theories and thus lead to opportunities for research. This is a way of "borrowing" from other subjects to deal with questions of the subject we are devoting to. It is just like a saying "Stones of other hills may serve to polish the jade from this hill". Widely reading in other fields would offer us inspiration in our devoting areas. Thus, we should not limit our minds or our concerning scope. We can draw useful suggestion from this point that we try to imitate the pattern other subjects to see how the innovation in them to come into being and transfer or apply its method into our own fields and there may turn out to be miracle results.

Third, consideration of the terminology in our discipline can yield innovative ways to illustrate it or even definitions. Usually, the terminology or concept of a subject can be a breakthrough point for our innovation. Thinking over the existing concepts of our fields for a long time, we can sometimes get some 
questions or puzzles in our minds toward the current field and then work on it to deliver a new and more proper definition and through this way, we are innovating.

\section{Conclusion}

Everything in the world is changing constantly. In academic fields, the innovation is so important that it can cause the academy improvement which is usually related to the progress of science and society of a country. We admit that there really exist some phenomena of not innovating well in academic fields which has obvious bad effects: underdeveloped academic field and weakened national power. We admit the contending in academic fields and think it to be a good phenomenon while we should avoid the repetitive jobs under blind imitation and we call for one's own voice---innovation. Innovation is a hard job while it is very useful and necessary. Fortunately, we have realized this importance and have got ideas of how to innovate: to imitate others' methodology and skill is an effective way to help one's own innovation but it is just a method not the final result we are expecting. Imitation is a process of learning, absorbing and at last creating while innovation is the key element we should pursue all our lives. To innovate in academic fields is of great value and significance just as what I have mentioned above. Therefore, we should begin to keep in our minds the innovation idea to innovate from us and then influence others to tell them to stop useless plagiarism and blind imitation in academic fields.

\section{References}

[1] C.A. Paxton, Developing Tsuru University's English Speech Syllabus Tsuru Bunka University's Journal, March 2003.

[2] Chen,E.X. http://www.bigyuwen.com/www/jstd/2005-12-27/1135634543d91200.html 2005-12.

[3] J. Bessen and E. Maskin, Sequential Innovation, Patents, and Imitation November 1999.

[4] Manakins Innovation and Imitation http://www.nairaland.com/nigeria/topic-12601.0.html. 